\title{
Acute fibrinous and organizing pneumonia: two case reports and literature review
}

\author{
Haihong Chen ${ }^{1 \dagger}$, Yukun Kuang ${ }^{1 \dagger}$, Xinyan Huang ${ }^{1}$, Ziyin Ye ${ }^{2}$, Yangli Liu' ${ }^{1}$, Canmao Xie ${ }^{1}$ and Ke-Jing Tang ${ }^{1 *}$ (D)
}

\begin{abstract}
Background: Acute fibrinous and organizing pneumonia (AFOP) is a rare histologic interstitial pneumonia pattern characterized by the intra-alveolar fibrin deposition and organizing pneumonia. Its clinical characteristics are still not well known and there is no consensus on treatment yet.

Case presentation: We report two female cases in their fifties diagnosed with AFOP confirmed by a second lung biopsy. Case 1 was idiopathic AFOP with manifestation of 6-week fever, dyspnea, and cough, while case 2 was secondary to systemic lupus erythematosus and fever was the major symptom. Their chest CT scans revealed bilateral multiple consolidations, predominantly in the lower lobes. Both cases were initially diagnosed with pneumonia, but did not improve after treatment with broad-spectrum antibiotics. In both cases, transbronchial biopsy and bronchoalveolar lavage fluid examination were inconclusive and the pathological diagnosis was confirmed by percutaneous lung biopsy. Both patients had a good clinical response to prednisone.

Conclusions: We report two rare AFOP cases to highlight the importance of awareness of this disease. We further perform the most comprehensive review to date in AFOP, including 150 patients since 2002. Consolidation was the most common imaging pattern, followed by ground-glass opacity and nodules. A lung biopsy is required for a definitive diagnosis. Corticosteroids is recommended as the most effective therapy, but treatment options should depend on the etiology and disease severity.
\end{abstract}

Keywords: Acute fibrinous and organizing pneumonia, Clinical characteristics, Biopsy, Pathology, Treatment

\section{Background}

Acute fibrinous and organizing pneumonia (AFOP), first described in 2002 by Beasley [1], is a rare histologic interstitial pneumonia pattern characterized by the intra-alveolar fibrin deposition and organizing pneumonia [2] deposition and organizing.

\footnotetext{
* Correspondence: tangkj@mail.sysu.edu.cn

${ }^{\dagger}$ Haihong Chen and Yukun Kuang contributed equally to this work.

'Division of Pulmonary and Critical Care Medicine, the First Affiliated Hospital of Sun Yat-sen University, Institute of Pulmonary Diseases, Sun Yat-sen University, Province Guangdong 510080 Guangzhou, People's Republic of China

Full list of author information is available at the end of the article
}

AFOP has been frequently misdiagnosed due to inadequate knowledge of its pathology. Its clinical features are still not well known and there is no consensus on treatment yet. Clinical outcomes vary considerably according to its diversities, but most cases have ended up with poor prognosis.

Here we present two cases with a pathologic diagnosis of AFOP at our tertiary hospital in China. Furthermore, we describe the most comprehensive literate review of the AFOP, to provide further detail of this disease for physicians.

\section{Case presentation}

\section{Case 1}

A 53-year-old female was transferred to our department with a 6-week history of dyspnea and cough with

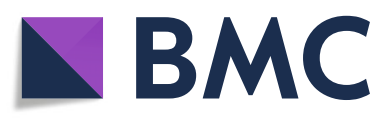

(c) The Author(s). 2021 Open Access This article is licensed under a Creative Commons Attribution 4.0 International License, which permits use, sharing, adaptation, distribution and reproduction in any medium or format, as long as you give appropriate credit to the original author(s) and the source, provide a link to the Creative Commons licence, and indicate if changes were made. The images or other third party material in this article are included in the article's Creative Commons licence, unless indicated otherwise in a credit line to the material. If material is not included in the article's Creative Commons licence and your intended use is not permitted by statutory regulation or exceeds the permitted use, you will need to obtain permission directly from the copyright holder. To view a copy of this licence, visit http://creativecommons.org/licenses/by/4.0/ The Creative Commons Public Domain Dedication waiver (http://creativecommons.org/publicdomain/zero/1.0/) applies to the data made available in this article, unless otherwise stated in a credit line to the data. 
sputum in December 2018. She also complained of intermittent fever, mild chest pain, fatigue, appetite loss and night sweats. At a local hospital, her chest CT scan demonstrated multiple consolidations bilaterally, predominantly in both lower lobes, with mildly enlarged mediastinal lymph nodes. She was treated by ceftriaxone and levofloxacin, but her symptoms did not improve. CT scans (Fig. 1A) performed prior to hospitalization revealed enlarging bilateral lung lesions. She had past medical history of uterine fibroids, beta thalassemia (heterozygosity) and iron deficiency anemia.

Laboratory data showed normal white blood cell count $\left(7.48^{*} 10^{\wedge} 9 / \mathrm{L}\right)$ with elevated serum C-reactive protein $(63.10 \mathrm{mg} / \mathrm{L})$ and erythrocyte sedimentation rate $(110 \mathrm{~mm} / \mathrm{h})$. Serum procalcitonin $(0.06 \mathrm{ng} / \mathrm{ml}), 1-3-\beta-\mathrm{D}$ Glucan $(<37.5 \mathrm{pg} / \mathrm{ml})$ and Galactomannan measurement (0.1) were within normal range, and interferon release test for tuberculosis was negative. Blood and sputum cultures were negative. Tumor markers, including CEA, CA125, CA199, AFP and serological investigations for connective tissue disease, such as anti-nuclear antibodies, anti-dsDNA antibody, anti-neutrophil cytoplasmic antibody, rheumatoid factor and immunoglobulin (IgA, IgG, IgM) were all negative. Bronchoscopy was performed and the bronchoalveolar lavage fluid (BALF) culture was negative. Pathology of transbronchial lung biopsy of left lateral basal segment revealed that the pulmonary alveolar structure was intact, with fibrotic thickened alveolar septa, infiltrated by a few lymphocytes. Alveolar cavities were filled with a large amount of fibrinous exudation, which raised the possibility of interstitial pneumonia.

On day 6th of admission, the patient had fever and chills again, with the highest temperature of $38.5{ }^{\circ} \mathrm{C}$. She was treated by intravenous moxifoxacin for 7 days, followed by imipenem-cilastatin, but she still had fever and developed tachypnea. On day 18th of admission, the chest CT showed that bilateral pulmonary lesions had progressed (Fig. 1B). Subsequently, Ultrasound-guided percutaneous lung biopsy was performed and histological examination demonstrated a large amount of fibrinous exudate in alveolar cavities, significantly widened alveolar septa, and a large number of lymphocytes, plasma cells and a few neutrophils. Organization foci composed of proliferative fibroblast was identified (Fig. 2). Combined with clinical details, the pathological finding raised possibility of AFOP. Acid fast stain, alcian blue stain, Grocott methenamine silver (GMS) and Periodic Acid-Schiff (PAS) stain were negative.

Intravenous corticosteroid (methylprednisolone, $80 \mathrm{mg} /$ day for 3 days, followed by $60 \mathrm{mg} / \mathrm{d}$ for 1 week and $40 \mathrm{mg} /$ day for another 1 week) was administered. Her clinical symptoms significantly improved and fever did not recur. At the 12th day of the steroid treatment,
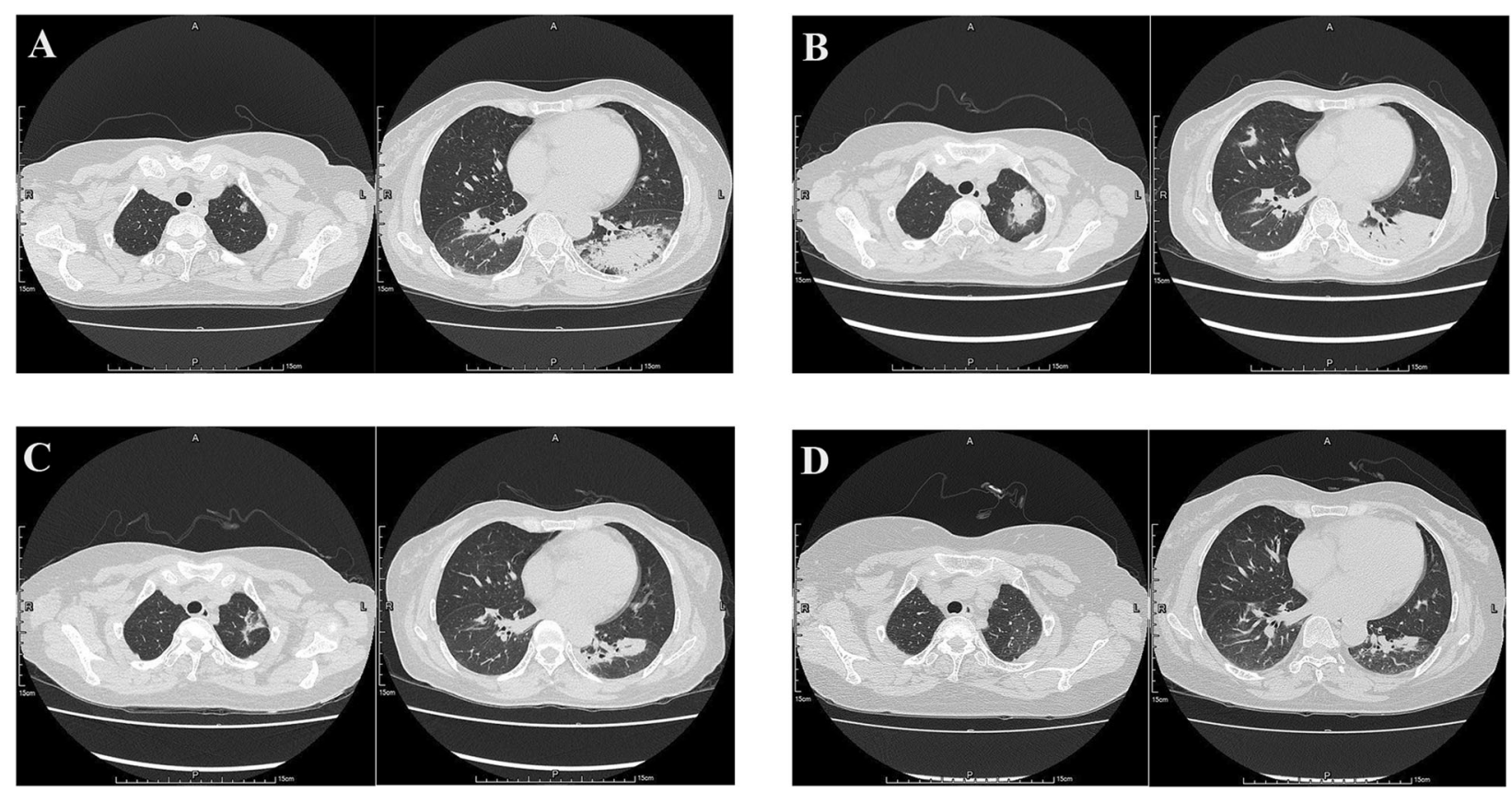

Fig. 1 The initial and follow-up CT images of case 1. A CT of one day before admission showed bilateral consolidations, predominantly in both lower lobes, with basal and subpleural distribution, and patchy-like ground-glass opacity in the left upper lobe. B CT images on day 18th of admission showed lesions progression. $\mathbf{C} C T$ images of follow-up at the 12th day of the steroid treatment and $\mathbf{D} C T$ of follow-up at 3rd month after discharge showed lesions absorption 


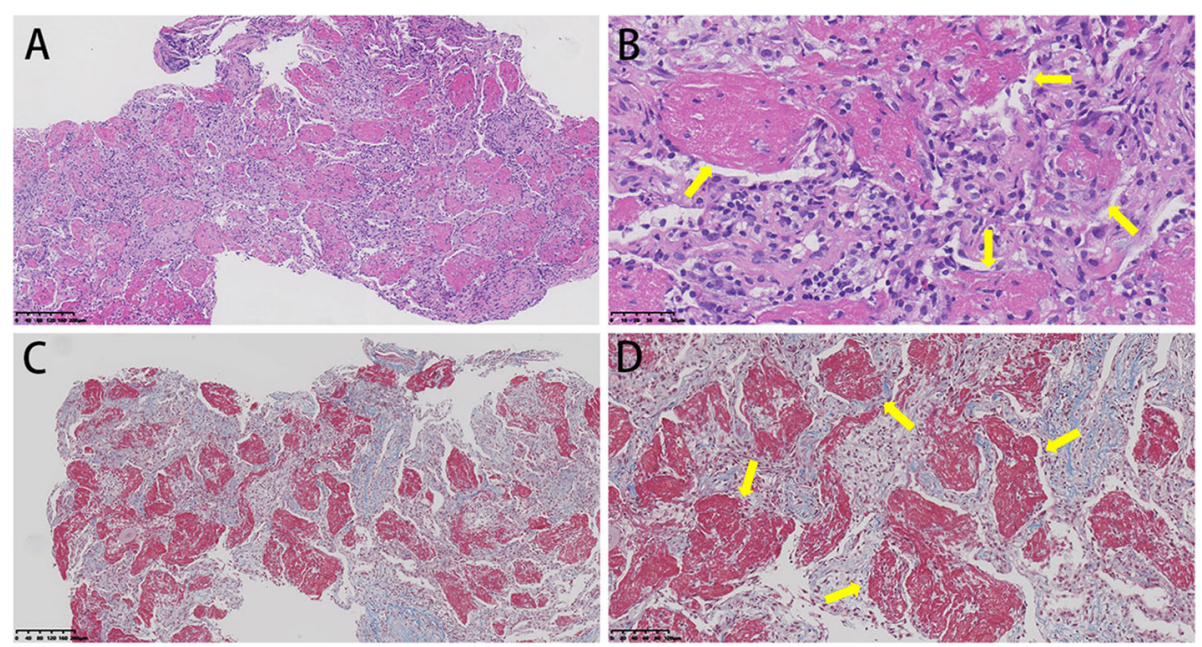

Fig. 2 Histologic findings of case 1 on lung biopsy. Hematoxylin and eosin stain $(\mathbf{A}, \times 100)(\mathbf{B}, \times 200)$ showed alveoli were filled with fibrinous exudate (arrows) without pulmonary hyaline membrane, the alveolar septum was thickened and infiltrated with a few lymphocytes, which were consistent with AFOP. Masson's trichrome stain $(\mathbf{C}, \times 100)(\mathbf{D}, \times 200)$ showed alveoli cavities were filled with fibrinous exudates (arrows)

\section{A}
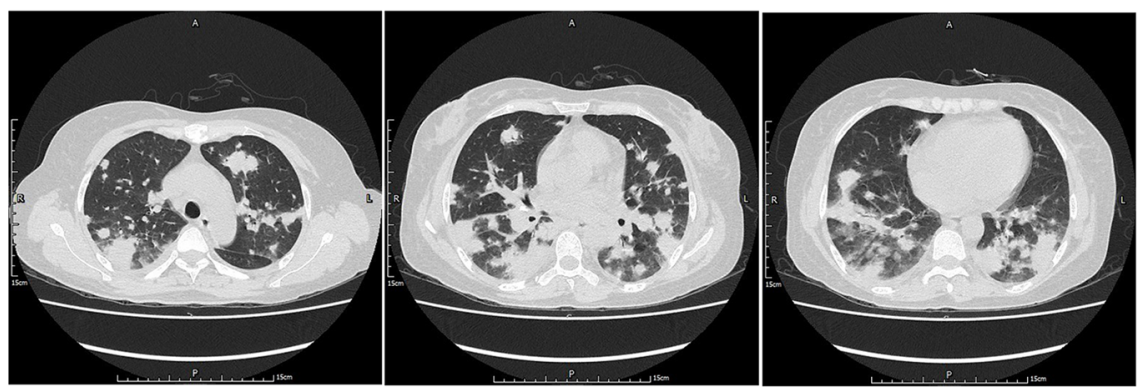

\section{B}
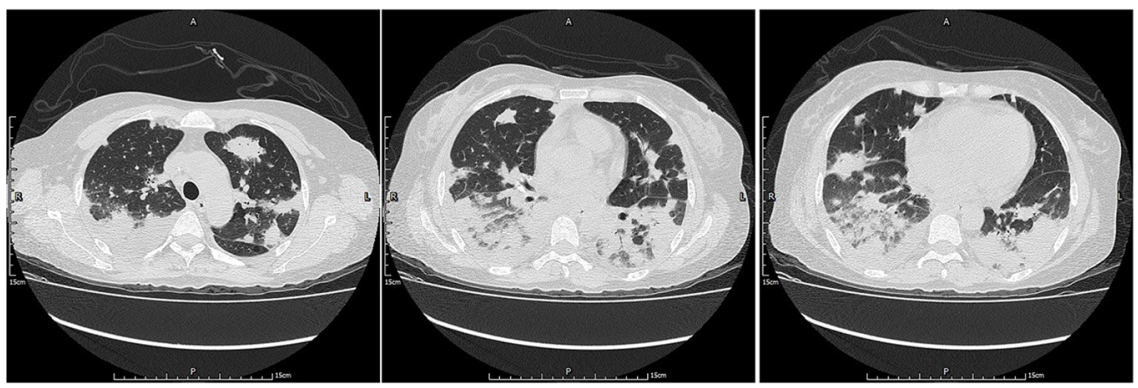

C
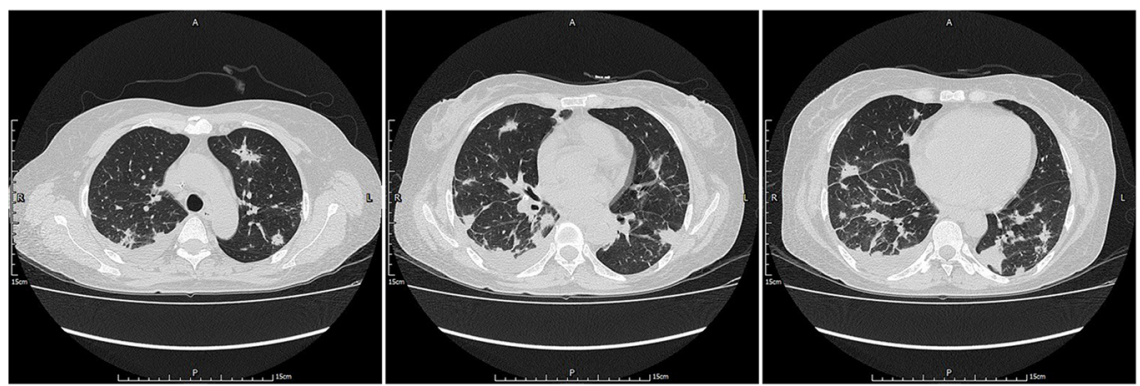

Fig. 3 The initial CT images and the follow-up CT images of case 2. A Chest CT on admission revealed multiple nodules, consolidations and patchy opacities in both lungs. B CT images on day 14th of admission showed bilateral lesions increased and enlarged. C CT images at the 7th day of the steroid treatment showed absorption of bilateral lung lesions 
consolidations in both lungs reduced (Fig. 1C). The patient discharged on a regular tapering schedule of methylprednisolone with outpatient follow-up. Relapse occurred and follow-up CT showed new lesions in the left upper lobe after the dose was reduced to $12 \mathrm{mg}$ around 9-month after discharge. She got improvement again after administration of methylprednisolone with the dose of $40 \mathrm{mg} /$ day.

\section{Case 2}

A 54-year-old non-smoking woman was admitted because of fever for 3 days. She had a history of systemic lupus erythematosus with secondary moderate anemia and had been treated with methylprednisolone and cyclophosphamide for 13 years.

Blood routine examination revealed elevated white blood cell count of $10.6^{*} 10^{\wedge} 9 / \mathrm{L}$ with neutrophil predominance. Anti-cardiolipin antibody, anti-nuclear antibodies and anti-SSA antibody were positive while other serum examination for autoimmune disease including anti-neutrophil cytoplasmic antibody, rheumatoid factor and Coombs test were negative. Blood and sputum cultures were negative as well as serum pneumococcal antigen. Serum IgM for influenza A and B virus, adenovirus, respiratory syncytial virus, Mycoplasma pneumoniae and Chlamydia pneumoniae was negative, while interferon release test for tuberculosis was positive. Tumor markers including CEA, CA125, CA199, NSE and AFP were negative. Chest CT revealed multiple nodules, consolidations and opacities in both lungs, with slightly enlarged mediastinal lymph nodes (Fig. 3A).
Moxifoxacin was administered initially for antiinfective therapy and then switched to meropenem and linezolid on day 6th. Antituberculous and antifungal therapy were also added. However, the patient had recurrent high fever with temperature up to $40.5{ }^{\circ} \mathrm{C}$. The patient underwent bronchoscopy and transbronchial lung biopsy. The pathology demonstrated fragments of bronchial mucosa and fibrinous exudate. Alcian blue and PAS stain and culture of BALF were negative.

Two weeks after admission, chest CT indicated an increase of nodules and consolidations in both lungs with new development of a small amount of pleural effusion bilaterally (Fig. 3B). Ultrasound-guided percutaneous lung biopsy was performed and the pathology revealed that alveoli were filled with fibrinous exudate and the fibrotic thickened alveolar septa were infiltrated by large amount of lymphocytes (Fig. 4). GMS stain was negative. These findings were mostly consistent with AFOP. High dose of intravenous methylprednisolone $(320 \mathrm{mg} / \mathrm{d}$ for 1 day and $200 \mathrm{mg} / \mathrm{d}$ for another 2 days, followed by $80 \mathrm{mg} /$ day for 1 week) was administered intravenously, resulting in improvement of clinical symptoms and chest radiography findings (Fig. 3C).

\section{Discussion and conclusions}

AFOP, first reported in 2002 in a case series involving 17 patients with acute respiratory failure [1], was defined as a subgroup of idiopathic interstitial lung disease [2] by the American Thoracic Society/European Respiratory Society statement in 2013. We performed a literature review of all reports of AFOP patients over the period from 2002 to 2019 , by conducting a thorough search in
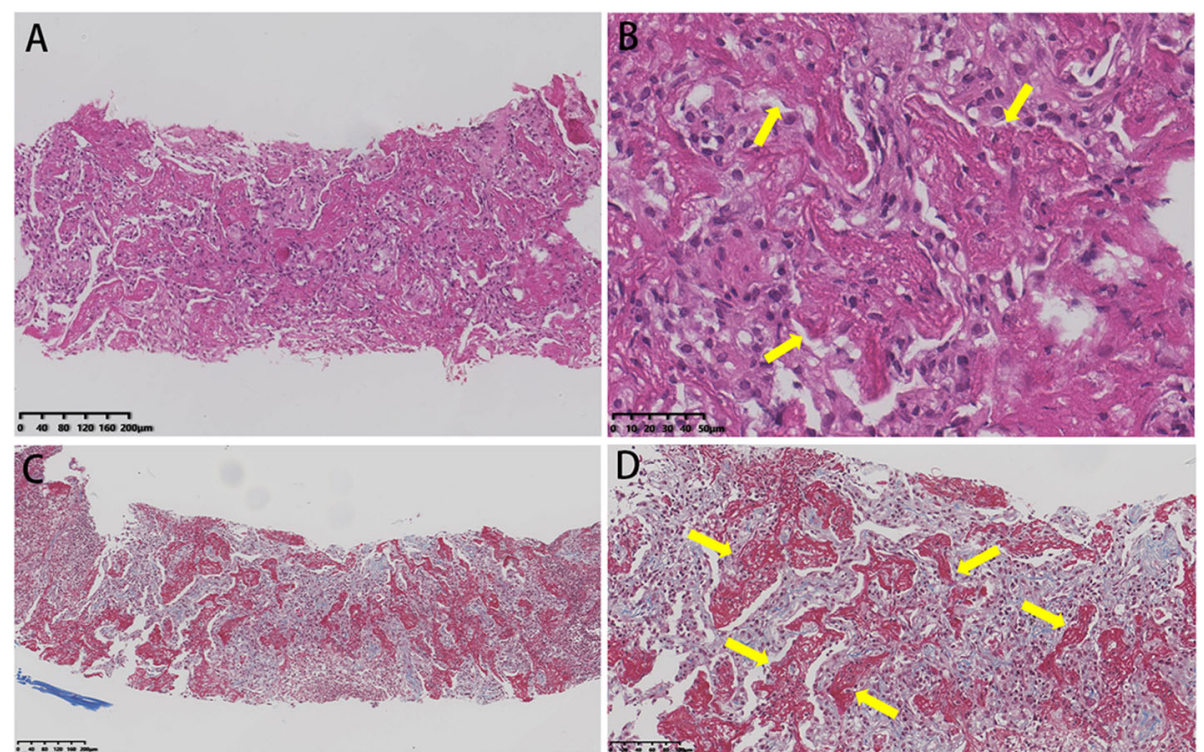

Fig. 4 Histologic findings of case 2 on lung biopsy. Hematoxylin and eosin stain $(\mathbf{A}, \times 100)(\mathbf{B}, \times 200)$ showed there was interstitial fibrosis and abundant of fibrous exudate filled in the alveoli(arrows), which was highlighted by Masson's trichrome stain $(\mathbf{C}, \times 100)(\mathbf{D}, \times 200)($ arrows) 
PubMed and Web of Science databases. The search was limited to English publications. A total of 81 eligible reports [3-26] with non-overlapped 148 suitable cases were qualified for the literature review and a total of 150 candidates (including two patients in our study) were served as the study population for this analysis.

AFOPs have been reported mainly in USA, Europe and Asia. There was no clear gender difference and the mean age was $54.3 \pm 15.8$ years (range, 38 days- 84 years) (Table 1). Our two reported patients were 53 and 54 years old. Fifty cases were diagnosed as idiopathic AFOP, while the other 100 cases were considered secondary AFOP, which were associated with a wide range of medical conditions or risk factors (Table 2). It should be noted that there were two cases caused by immune checkpoint inhibitor (Nivolumab and pembrolizumab) $[8,21]$, which is one of the most effective treatments for metastatic melanoma and advanced non-small cell lung cancer in recent years. Smoking appeared not to be a risk factor.

Clinical manifestations of AFOP were nonspecific. Most common symptoms were dyspnea, cough (87 had a non-productive cough) and fever (Table 1). Other symptoms included hemoptysis, fatigue, chills, night sweat and weight loss. One patient was asymptomatic. Fever was considered to be more common in AFOP when compared with other forms of interstitial

Table 1 Clinical characteristic and prognosis of patients with AFOP

\begin{tabular}{|c|c|c|c|}
\hline Variable & $\begin{array}{l}\text { Total } \\
(n=150)\end{array}$ & $\begin{array}{l}\text { Idiopathic-AFOP } \\
(n=50)\end{array}$ & $\begin{array}{l}\text { Secondary-AFOP } \\
(n=100)\end{array}$ \\
\hline Age (y) & $54.3 \pm 15.8$ & $57.6 \pm 14.1$ & $52.3 \pm 16.5$ \\
\hline Gender, male ${ }^{a}$ & $65 / 128(51)$ & $23 / 50(46)$ & $42 / 78(42)$ \\
\hline \multicolumn{4}{|l|}{ Symptoms } \\
\hline Fever & $64(43)$ & $27(54)$ & $37(37)$ \\
\hline Dyspnea & $108(72)$ & $40(80)$ & $68(68)$ \\
\hline Cough & $106(71)$ & $36(72)$ & $70(70)$ \\
\hline Chest pain & $24(16)$ & $14(28)$ & $10(10)$ \\
\hline Hemoptysis & $9(6)$ & $5(10)$ & $4(4)$ \\
\hline Progression, acute ${ }^{a}$ & $41 / 103(40)$ & 16/41(39) & $25 / 62(40)$ \\
\hline Smoking status ${ }^{a}$ & $22 / 58(38)$ & 8/28(29) & $14 / 31(45)$ \\
\hline \multicolumn{4}{|l|}{ CT pattern ${ }^{a}$} \\
\hline Consolidation & $79 / 145(54)$ & $32 / 46(70)$ & 47/99(47) \\
\hline GGO & $61 / 145(42)$ & $14 / 46(30)$ & 47/99(47) \\
\hline Nodulars & $29 / 145(20)$ & $10 / 46(22)$ & 19/99(19) \\
\hline \multicolumn{4}{|l|}{ Mortality } \\
\hline All-cause death & $59(39.3)$ & $10(20)$ & $49(49)$ \\
\hline Related death & $49(32.7)$ & $10(20)$ & $39(44)$ \\
\hline
\end{tabular}

Values are mean \pm SD or $\mathrm{n}(\%)$

AFOP Acute fibrinous organizing pneumonia, GGO Ground-glass opacity

${ }^{a}$ not including all the cases for some were not reported pneumonia [27]. The disease progression was acute in 41 patients, subacute in 62 patients, and not specific in the rest.

The most common CT findings were bilateral diffuse patchy consolidations, often with basal or peripheral dominance. There were 116 cases showing bilateral involvement. The most common imaging pattern was consolidation in 79 patients, of which 28 cases also demonstrated ground-glass opacity(GGO); other common patterns were GGO in 61 patients and nodules in 29 cases (Table 1). Consolidation was more frequently demonstrated in idiopathic-AFOP patients, but conversely, GGO was more frequently demonstrated in secondary-AFOP patients. Pleural involvement was uncommon, with mild bilateral effusion in 7 cases, right pleural effusion in 3 patients and pneumothorax in 2 patients. In addition, CT scan showed interstitial pneumonia in 11 cases and a solitary mass in 2 cases. All of these atypical findings were exclusively seen in the secondary-AFOP.

The nonspecific clinical features frequently resulted in misdiagnosis and a delay in the diagnosis of AFOP. At the time of initial diagnosis, most cases were misdiagnosed as lung infection, while a few cases were misdiagnosed as lung cancer. Beasley and his colleagues [1] described a mean time from onset of symptoms to diagnosis of 19 days, and Gomes et al. [4] reported a mean time of 43.9 days.

The diagnosis of AFOP depends on the pathology of a lung biopsy specimen. The lung lesion tissue was obtained by surgical lung biopsy (mainly by video-assisted thoracic surgery) in 60 patients, transbronchial lung biopsy in 43 patients, image-guided (CT- or ultrasoundguided) percutaneous lung biopsy in 31 patients, autopsy in 13 patients and unspecified in 3 patients. BALF was performed in 28 patients before pathological diagnosis and no conclusive pathology were found. For both of our cases, either BALF culture or transbronchial biopsy was conclusive. To confirm the diagnosis, a second lung biopsy (percutaneous lung biopsy) was performed in our two cases and the pathology was consistent with AFOP.

The main pathological features of AFOP are intra- alveolar fibrin deposition in the form of fibrin "balls" and patchy organized pneumonia [1]. Its minor features are acute or chronic inflammation and type II pneumocyte hyperplasia adjacent to areas of fibrin deposition, alveolar septal expansion with myxoid degeneration, and only minimal changes in the pulmonary tissue areas without fibrinous exudation. The pathological differential diagnoses include bronchiolitis obliterans organizing pneumonia(OP), eosinophil pneumonia(EP), and diffuse alveolar damage(DAD) [1]. Fibrin deposits could appear in both the DAD and OP patterns, but they are not a predominant histologic finding, and do not show the 
Table.2 Possible causes or associations with AFOP

Associations

Lung transplantation(LT)

Autoimmune diseases/CTD

Medications/Drugs

Infection

Hematological malignances

HSCT

Solid tumor

Environmental exposures
Juvenile dermatomyositis

Systemic sclerosis

Polymyositis

Sjogren's syndrome $\quad 2$

Anti-synthetase syndrome $\quad 2$

Systemic lupus erythematosus 2

Collagen vascular disease 1

CTD (with asbestos and fiberglass exposure) ${ }^{\mathrm{a}}$

Fibromyalgia 1

Severe AA (suspected to be autoimmune) 1

Amiodarone (1 with zoologist exposure a)

Abacavir 1

Decitabine 2

Bleomycin (1 with Aba infection ${ }^{\mathrm{a}}$ ) 3

Sirolimus

Everolimus

Nivolumab

Cocaine 1

Azacytidine 1

Adjuvant chemotherapy\&radiotherapy 1

Pembrolizumab 1

14

Lung abscess 1

Haemophilus influenza 1

Sepsis 1

Chlamydia pneumoniae 1

Mycoplasma pneumoniae 1

Mycobacterium tuberculosis 1

Aspergillosis

Respiratory syncytial virus 1

$\mathrm{Aba}^{\mathrm{a}}$

Pneumocystis jirovecii (and HIV) ${ }^{\text {a }} 1$

Influenza virus (after double LT) 1

Not mentioned 2

Lymphoma

Acute leukemia $\quad 2$

Myelodysplastic syndrome $\quad 2$

(3 of lymphoma, 2 of leukemia) 5 
Table.2 Possible causes or associations with AFOP (Continued)

\begin{tabular}{|c|c|c|}
\hline Associations & & $\mathbf{n}$ \\
\hline & Zoologist exposed to exotic animals(with usage of amiodarone ) $)^{a}$ & 1 \\
\hline & Hair spay & 1 \\
\hline & Coal miner & 1 \\
\hline & Asbestoe and fiberglass exposure (with CTD) ${ }^{a}$ & 1 \\
\hline & Poultry & 1 \\
\hline & Herbicide or pesticide & 1 \\
\hline & Construction worker(with Aba infection $)^{a}$ & 1 \\
\hline & Risk occupational exposure (not specified) & 1 \\
\hline Whipple's disea & & 1 \\
\hline Chronic glomer & & 1 \\
\hline HIV & One with Pneumocystis jirovecii infection ${ }^{a}$ & 2 \\
\hline
\end{tabular}

AFOP Acute fibrinous organizing pneumonia, HSCT Hematopoietic stem cell transplantation, CTD Connective tissue disease, AA aplastic anemia, Aba Acinetobacter baumanii

${ }^{a}$ the case was combined with another association

intra-alveolar fibrin ball pattern. The AFOP further differs from DAD in that classic hyaline membranes are absent, and differs from EP by the lack of prominent eosinophils [1]. Surgery biopsy is the best for tissue sampling to make AFOP diagnosis, as it can minimize the missing area for hyaline membranes in DAD. However, we suggest that the method of lung biopsy should be based on the location of lung lesions and patients tolerance to the operations.

Regarding treatment for AFOP, the most common therapy was corticosteroids, in 132 of 150 patients $(88 \%)$. There is no consensus on the dose and duration of corticosteroids. Twelve patients were administered with a pulse therapy of corticosteroids (prednisone $500 \mathrm{mg} /$ day to methylprednisolone $1000 \mathrm{mg} /$ day), and 4 died (one of them from other complications). Relapse may occur during steroid tapers and symptoms mostly could relieve again after higher doses were resumed. Immunosuppressive agents such as cyclophosphamide, mycophenolate mofetil, cyclosporine, azathioprine, tacrolimus etc. had been tried in 17 patients, all combined with corticosteroids, with varying results. AFOPs secondary to autoimmune diseases may benefit most from immunosuppressant. Other reported effective drugs were antibiotics (especially for those caused by infection), etanercept [25], indomethacin [28] and immunoglobulin [23].

Discontinuation of relevant drugs is of critical important. In 13 drug-related AFOP patients, 9 candidates completely recovered by drug discontinuation with corticosteroids. However, two patients died and another two died of other complication. Partial lobectomy/lesion resection was reported as a successful cure when the disease was relatively localized [29]. Hematopoietic stem cell transplantation [30] or lung transplantation [6,30, 31] might be an option to treat AFOP which was refractory to medical treatment. However, further studies are required to follow up for possible recurrence of AFOP.

Among 150 reported cases, 59 (39\%) patients died with 10 cases being unrelated to AFOP) (Table 1). AFOP after lung transplantation seemed to have relatively poor prognosis [26]. Patients with acute-onset or secondaryAFOP had higher mortality rate than their corresponding cases. Furthermore, we discovered that AFOP with development of dyspnea, GGO in CT scan and lack of consolidation seemed to be associated with poor prognosis. However, further evaluation is required to confirm this finding.

In conclusion, we performed the so far most comprehensive review regarding AFOP, including 150 patients over an 18-year period. Given the various etiologies, nonspecific clinical presentations and insufficient understanding of pathology, AFOP probably had been under diagnosis or misdiagnosed. Our two cases highlight the importance of being aware of this uncommon pattern of acute lung injury. AFOP should be considered one of differentials in suspected pulmonary infection cases unresponsive to empirical antibiotic therapy, especially with CT patterns of basal or peripheral-predominant consolidation, with or without GGO or nodular opacities. Dedicated tissue sampling and thorough pathologic evaluation are essential for diagnosis and therapeutic guidance and hence to yield satisfactory outcome. While corticosteroids was recommended as the most effective therapy, other treatment options should be considered depending on the etiology and disease severity.

\section{Abbreviations}

AFOP: Acute fibrinous and organizing pneumonia; BALF: Bronchoalveolar lavage fluid; CTD: Connective tissue disease; DAD: Diffuse alveolar damage; EP: Eosinophil pneumonia; GGO: Ground-glass opacity; GMS: Grocott methenamine silver; OP: Organizing pneumonia; PAS: Periodic Acid-Schiff 


\section{Acknowledgements}

Not applicable.

\section{Authors' contributions}

$K T, C X, H C$ and $Y K$ conceived and designed the study. KT, HC, YK and XH contributed to data acquisition and $\mathrm{HC}$ and $\mathrm{YK}$ were the major contributors. $H C$, YK and XH take responsibility for data analysis. HC, YK, XH, and YL drafted the manuscript and $K T$ and $C X$ revised it. ZY provided critical contribution to the processing and interpretation of the pathological findings. All authors read and approved the final manuscript.

\section{Funding}

No funding was obtained for this study.

\section{Availability of data and materials}

The datasets used and analysed during the current study are available from the corresponding author on reasonable request.

\section{Declarations}

\section{Ethics approval and consent to participate}

The study was approved by the Institutional Research Ethics Committee of the First Affiliated Hospital of Sun Yat-Sen University. The institutional review board waived the requirement for approval and signed informed consent form because this study was not an intervening trial and retrospective in nature.

\section{Consent for publication}

Written informed consent was obtained from both patients for the publication of case reports and any accompanying images.

\section{Competing interests}

The authors declare that they have no competing interests.

\section{Author details}

'Division of Pulmonary and Critical Care Medicine, the First Affiliated Hospital of Sun Yat-sen University, Institute of Pulmonary Diseases, Sun Yat-sen University, Province Guangdong 510080 Guangzhou, People's Republic of China. ${ }^{2}$ Department of Pathology, the First Affiliated Hospital of Sun Yat-sen University, Province Guangdong, Guangzhou, People's Republic of China.

Received: 15 January 2021 Accepted: 25 September 2021 Published online: 10 October 2021

\section{References}

1. Beasley MB, Franks TJ, Galvin JR, Gochuico B, Travis WD. Acute fibrinous and organizing pneumonia: a histological pattern of lung injury and possible variant of diffuse alveolar damage. Arch Pathol Lab Med. 2002;126(9):106470. https://doi.org/10.1043/0003-9985(2002)126<1064:AFAOP>2.0.CO;2.

2. Johkoh T, Fukuoka J, Tanaka T. Rare idiopathic interstital pneumonias (IIPs) and histologic patterns in new ATS/ERS multidisciplinary classification of the IIPs. Eur J Radiol Mar. 2015;84(3):542-6. https://doi.org/10.1016/j.ejrad.2 014.11.032.

3. Kuza C, Matheos T, Kathman D, Heard SO. Life after acute fibrinous and organizing pneumonia: a case report of a patient 30 months after diagnosis and review of the literature. J Crit Care. 2016;31(1):255-61. https://doi.org/1 0.1016/j.jcrc.2015.10.002

4. Gomes R, Padrao E, Dabo H, et al. Acute fibrinous and organizing pneumonia: a report of 13 cases in a tertiary university hospital. Medicine (Baltimore). 2016;95(27):e4073. https://doi.org/10.1097/MD.0000000000004 073.

5. Bansal S, Joshi P, Bhatt R, Goyal K, Mishra M, Kumar S. Acute fibrinous organizing pneumonia: a rare lung pathology. Monaldi Arch Chest Dis. 2019;89(2). https://doi.org/10.4081/monaldi.2019.1016.

6. Campisi A, Dell'Amore A, Bertolaccini L, et al. Urgent lung transplantation in acute fibrinous and organizing pneumonia: a sliding door or a new perspective? Gen Thorac Cardiovasc Surg. 2019;68(2):136-41. https://doi. org/10.1007/s11748-019-01183-7.

7. Kwon KY. Pathological interpretation of connective tissue disease-associated lung diseases. Yeungnam Univ J Med. 2019:36(1):8-15. https://doi.org/10.12 701/yujm.2019.00101.
8. Larsen BT, Chae JM, Dixit AS, Hartman TE, Peikert T, Roden AC. Clinical and histopathologic features of immune checkpoint inhibitor-related pneumonitis. Am J Surg Pathol. 2019;43(10):1331-40. https://doi.org/10. 097/PAS.0000000000001298.

9. Lu J, Yin $Q$, Zha Y, et al. Acute fibrinous and organizing pneumonia: two case reports and literature review. BMC Pulm Med. 2019:5(1):141. https://doi. org/10.1186/s12890-019-0861-3

10. Santos C, Oliveira RC, Serra P, et al. Pathophysiology of acute fibrinous and organizing pneumonia - clinical and morphological spectra. Pathophysiology. 2019;26(3-4):213-7. https://doi.org/10.1016/j.pathophys.2 019.04.001.

11. Shintani R, Oda T, Niwa T, et al. Transbronchial lung cryobiopsy in idiopathic acute fibrinous and organizing pneumonia. Respir Med Case Rep. 2019;28: 100888. https://doi.org/10.1016/j.rmcr.2019.100888.

12. Wang $K$, Du $X$, Wu Q, Cheng D. A case report of acute fibrinous and organizing pneumonia. Medicine. 2019;98(49):e18140. https://doi.org/10.1 097/md.0000000000018140.

13. Wang $Y$, Li Y, Wang $Q$, Zhang L, Li J, Zhu C. Acute fibrinous and organizing pneumonia. Medicine. 2019;98(8):e14537. https://doi.org/10.1097/md. 0000000000014537

14. Chiu KY, Li JG, Gu YY. A case report of acute fibrinous and organizing pneumonia with pneumothorax and avian exposure history. Clin Respir J. 2018;12(2):811-5. https://doi.org/10.1111/cri.12553.

15. Kim JY, Doo KW, Jang HJ. Acute fibrinous and organizing pneumonia: Imaging features, pathologic correlation, and brief literature review. Radiol Case Rep. 2018;13(4):867-70. https://doi.org/10.1016/j.radcr.2018.04.028.

16. Ning YJ, Ding PS, Ke ZY, Zhang YB, Liu RY. Successful steroid treatment for acute fibrinous and organizing pneumonia: a case report. World I Clin Cases. 2018;6(15):1053-8. https://doi.org/10.12998/wjcc.v6.i15.1053.

17. Wang $Y$, Zhao $S$, Du G, et al. Acute fibrinous and organizing pneumonia as initial presentation of primary Sjogren's syndrome: a case report and literature review. Clin Rheumatol. 2018:37(7):2001-5. https://doi.org/10.1007/ s10067-018-4128-9.

18. Arnaud D, Surani Z, Vakil A, Varon J, Surani S. Acute fibrinous and organizing pneumonia: a case report and review of the literature. Am J Case Rep. 2017:24:1242-6.

19. Chen S, Zhou H, Yu L, Tong B, Xiao Z, Fan S. A case of herbicide-induced acute fibrinous and organizing pneumonia? BMC Pulm Med. 2017:13(1):203. https://doi.org/10.1186/s12890-017-0547-7.

20. Fasanya A, Gandhi V, DiCarlo C, Thirumala R. Acute fibrinous and organizing pneumonia in a patient with Sjogren's syndrome. Respir Med Case Rep. 2017;20:28-30. https://doi.org/10.1016/..rmcr.2016.11.010

21. Ishiwata T, Ebata T, Iwasawa S, et al. Nivolumab-induced Acute Fibrinous and Organizing Pneumonia (AFOP). Intern Med. 2017;56(17):2311-2315. https://doi.org/10.2169/internalmedicine.8271-16.

22. Jabbour R, Kumar H, Alvi $\mathrm{S}$, et al. An unusual presentation of acute fibrinous and organizing pneumonia. Am J Case Rep. 2017;15:532-6.

23. Kashif M, Arya D, Niazi M, Khaja M. A rare case of necrotizing myopathy and fibrinous and organizing pneumonia with anti-E antisynthetase syndrome and SSA antibodies. Am J Case Rep. 2017;18:448-53. https//doi.org/10.12659/ajcr.903540.

24. Nieto-Codesido I, Hermida-Romero T, Marcos PJ. Subacute pneumonia as a manifestation of acute fibrinous and organizing pneumonia. Arch Bronconeumol. 2017;53(3):167-8. https://doi.org/10.1016/j.arbres.2016.07.001 Neumonia subaguda como manifestacion de una neumonia organizada fibrosante aguda.

25. Simmons GL, Chung HM, McCarty JM, et al. Treatment of acute fibrinous organizing pneumonia following hematopoietic cell transplantation with etanercept. Bone Marrow Transplant. 2017;52(1):141-3. https://doi.org/10.1 038/bmt.2016.197.

26. Paraskeva M, McLean C, Ellis S, et al. Acute fibrinoid organizing pneumonia after lung transplantation. Am J Respir Crit Care Med. 2013;187(12):1360-8 https://doi.org/10.1164/rccm.201210-18310C.

27. Feinstein MB, DeSouza SA, Moreira AL, et al. A comparison of the pathological, clinical and radiographical, features of cryptogenic organising pneumonia, acute fibrinous and organising pneumonia and granulomatous organising pneumonia. J Clin Pathol. 2015;68(6):441-7. https://doi.org/10.113 6/jclinpath-2014-202626

28. Zhou CX, Tang TT, Huang LJ, et al. Methylprednisolone combined with lowdose indomethacin treating acute fibrinous and organizing pneumonia after a surgical resection of rectal adenocarcinoma: a case report and literature review. Eur Rev Med Pharmacol Sci. 2016;20(10):13. 
29. Santos C, Fradinho F, Catarino A. Acute fibrinous and organizing pneumonia. Rev Port Pneumol. 2010;16(4):607-16. https://doi.org/10.1016/ s0873-2159(15)30055-6 Pneumonia aguda fibrinosa e organizante.

30. Labarinas S, Gumy-Pause F, Rougemont AL, et al. Is acute fibrinous and organizing pneumonia the expression of immune dysregulation? J Pediatr Hematol Oncol. 2013;35(2):139-43. https://doi.org/10.1097/MPH.0b013e3182 7 e5782.

31. Renaud-Picard B, Degot T, Biondini D, et al. Successful lung retransplantation in a patient with acute fibrinous and organizing pneumonia: a case report. Transplant Proc. 2015;47(1):182-5. https://doi. org/10.1016/j.transproceed.2014.08.039.

\section{Publisher's Note}

Springer Nature remains neutral with regard to jurisdictional claims in published maps and institutional affiliations.

Ready to submit your research? Choose BMC and benefit from:

- fast, convenient online submission

- thorough peer review by experienced researchers in your field

- rapid publication on acceptance

- support for research data, including large and complex data types

- gold Open Access which fosters wider collaboration and increased citations

- maximum visibility for your research: over $100 \mathrm{M}$ website views per year

At BMC, research is always in progress.

Learn more biomedcentral.com/submissions 